\title{
TAL Effectors with Avirulence Activity in African Strains of Xanthomonas oryzae pv. oryzae
}

\author{
Marlène Lachaux ${ }^{1}$, Emilie Thomas ${ }^{1}$, Adam J. Bogdanove ${ }^{2}$, Boris Szurek ${ }^{1 *}$ (10 and Mathilde Hutin ${ }^{1 *}$
}

\begin{abstract}
Background: Xanthomonas oryzae pv. oryzae (Xoo) causes bacterial leaf blight, a devastating disease of rice. Among the type-3 effectors secreted by Xoo to support pathogen virulence, the Transcription Activator-Like Effector (TALE) family plays a critical role. Some TALEs are major virulence factors that activate susceptibility (S) genes, overexpression of which contributes to disease development. Host incompatibility can result from TALE-induced expression of so-called executor $(E)$ genes leading to a strong and rapid resistance response that blocks disease development. In that context, the TALE functions as an avirulence (Avr) factor. To date no such avirulence factors have been identified in African strains of XoO.
\end{abstract}

Results: With respect to the importance of TALEs in the Rice-Xoo pathosystem, we aimed at identifying those that may act as Avr factor within African Xoo. We screened 86 rice accessions, and identified 12 that were resistant to two African strains while being susceptible to a well-studied Asian strain. In a gain of function approach based on the introduction of each of the nine tal genes of the avirulent African strain MAl1 into the virulent Asian strain PXO99 A, four were found to trigger resistance on specific rice accessions. Loss-of-function mutational analysis further demonstrated the avr activity of two of them, talD and tall, on the rice varieties IR64 and CT13432 respectively. Further analysis of Tall demonstrated the requirement of its activation domain for triggering resistance in CT13432. Resistance in 9 of the 12 rice accessions that were resistant against African Xoo specifically, including CT13432, could be suppressed or largely suppressed by trans-expression of the truncTALE tal2h, similarly to resistance conferred by the Xal gene which recognizes TALEs generally independently of their activation domain.

Conclusion: We identified and characterized TaID and Tall as two African Xoo TALEs with avirulence activity on IR64 and CT13432 respectively. Resistance of CT13432 against African Xoo results from the combination of two mechanisms, one relying on the Tall-mediated induction of an unknown executor gene and the other on an Xa1-like gene or allele.

Keywords: Rice, Bacterial leaf blight, truncTALE/ITALE, Germplasm, Executor gene, Xa1-like resistance

*Correspondence: boris.szurek@ird.fr; mathilde.hutin@ird.fr

${ }^{1}$ Plant Health Institute of Montpellier, Univ Montpellier, IRD, CIRAD, INRAE,

Institut Agro, Montpellier, France

Full list of author information is available at the end of the article

\section{Introduction}

Cultivated plants constantly face multiple abiotic and biotic stresses, the latter of which are estimated to cause from 17 to $30 \%$ of global yield losses on five of the most important crops including rice (Savary et al. 2019). Rice (Oryza sativa L.) is one of the most widely cultivated crops around the world and a staple food for much of the developing world (Ainsworth 2008). A major threat to rice production in Asia and Africa is bacterial leaf 
blight (BLB) caused by the bacterial phytopathogen Xanthomonas oryzae pv. oryzae (Xoo). BLB may indeed cause up to $50 \%$ of yield loss depending on rice variety, growth stage of infection, geographic location and environmental conditions (Liu et al. 2014). Xoo enters leaves through hydathodes or wounds. Bacteria then multiply in the intercellular spaces of the underlying epitheme prior to reaching the xylem vessels and propagating into the plant. BLB symptoms are water-soaked lesions that spread following the bacteria's progression down the leaf and become chlorotic and then necrotic (Niño-Liu et al. 2006).

As do many pathogenic gram-negative bacteria, Xoo uses a type- 3 secretion system (T3SS) to secrete into the host cytoplasm a cocktail of type- 3 effectors (T3Es) that can be classified as transcription activator-like (TAL) effectors and non-TAL effectors. While the latter include a diverse array of effector families with various molecular activities, members of the TAL effector (TALE) family function as eukaryotic transcription factors that bind in a sequence-specific manner to the promoters of target genes in the host cells. Repeat-variable diresidues (RVDs) located at positions 12th and 13th of each of several contiguous repeats in a central domain of TALEs determine the DNA sequence binding specificity of the protein, one repeat to one nucleotide (Boch et al. 2009; Moscou and Bogdanove 2009). The target sequence, unique to each TALE, is called the effector binding element (EBE). Some Xoo TALEs are major virulence factors, targeting susceptibility $(S)$ genes. Upregulation of $S$ genes by TALEs contributes to disease development. $S$ genes characterized to date for BLB mainly encode clade-3 SWEET sugar uniporters that may increase the abundance of apoplastic sugar to the benefit of the pathogen, or transcription factors that regulate so far unknown secondary targets promoting host susceptibility (Garcia-Ruiz et al. 2021).

Forty-six genes, several dominant and some recessive, individually govern rice resistance against Xoo. Twelve have been cloned and nine are TALE-dependent, reflecting the crucial role of TALEs in the interaction (Jiang et al. 2020). Recessive resistance often involves mutations within the EBE of an $S$ gene to prevent the TALE-DNA interaction and consequent $S$ gene induction. This is well illustrated by the non-TALE-inducible $x a 13, x a 25$ and $x a 41$ loss-of-susceptibility alleles of the major $S$ genes OSSWEET11, OSSWEET13, and OSSWEET14, respectively (Chu et al. 2006; Liu et al. 2011; Hutin et al. 2015). Dominant resistance is often triggered by TALE-mediated induction of so-called executor $(E)$ genes, expression of which leads to rapid plant cell death that blocks disease development (Boch et al. 2014). Four $E$ genes, namely $\mathrm{Xa7}, \mathrm{Xa10}, \mathrm{Xa23}, \mathrm{Xa27}$, and their respective matching tal genes, avrXa7, avrXa10, avrXa23, avrXa27, have been cloned and characterized (Hopkins et al. 1992; Gu et al. 2005; Tian et al. 2014; Wang et al. 2014, 2015; Chen et al. 2021; Luo et al. 2021). These tal genes are only present in Asian strains of Xoo and no $E$ genes induced by African Xoo TALEs have been identified to date. $E$ genes so far code for small proteins with transmembrane domains, and the molecular mechanisms underlying their function are still far from being understood (Zhang et al. 2015; Chen et al. 2021). Another type of dominant resistance is conferred by receptor-like kinases (RLK), such as Xa3/ Xa26 (Sun et al. 2004; Xiang et al. 2006) and Xa21 (Song et al. 1995), but also Xa4 which encodes a cell wall-associated kinase (Hu et al. 2017). Finally, the last category are genes encoding nucleotide-binding domain leucinerich repeat containing receptors (NLRs) such as $X a 1$ and its apparent alleles Xo1, Xa2, Xa14, Xa31(t) and Xa45(t) (Ji et al. 2020; Read et al. 2020a; Zhang et al. 2020). We consider the latter genes "apparent" alleles because Xo1 resides in a cluster of NLR genes, the number of which varies among rice genotypes, making orthology uncertain. Xa1 and Xo1 were shown to mediate resistance in response to TALEs generally, independently of their specific RVD sequence, and with no requirement for the transcriptional activation domain (Ji et al. 2016; Triplett et al. 2016; Read et al. 2020a). A variant class of TALEs called interfering (iTALE) or truncated (truncTALE) TALEs suppress $\mathrm{Xa1} / \mathrm{Xo1}$-mediated resistance, and the truncTALE Tal2h has been demonstrated to interact with Xo1 (Ji et al. 2016; Read et al. 2016, 2020a). Whether this interaction is direct, and whether Xo1 interacts with TALEs to mediate resistance remains to be elucidated. Analysis of functional apparent alleles of $\mathrm{Xa1}$ and $\mathrm{Xo1}$ revealed the absence of an intervening motif present in non-functional alleles, and differences in the number (4 to 7) of central tandem repeats that might explain differences in their activity (Zhang et al. 2020). Interestingly, most Asian strains of Xoo harbor iTALEs/truncTALEs while African strains do not, explaining why African strains are widely controlled by $\mathrm{Xa1}, \mathrm{Xo1}$ or functional homologs (Ji et al. 2016; Read et al. 2016, 2020a).

Previous studies demonstrated that African Xoo are genetically distant from Asian Xoo and closer to Xanthomonas oryzae pv. oryzicola (Xoc) (Poulin et al. 2015), which causes bacterial leaf streak (BLS). A characteristic feature of African Xoo is their small TALome (set of tal genes) consisting of 8-9 genes, relative to Asian Xoo which carry up to $19 \mathrm{tal}$ genes. Moreover, no TALE is conserved between Asian and African strains (Lang et al. 2019). Comparative analysis of the TALome of several African strains revealed six groups of polymorphic TALEs based on their RVD sequences, including TalA, TalB, TalD, TalF, TalH, and Tall (Doucouré et al. 2018; Tran et al. 2018). African Xoo are also distinguished by 
a reduced number of races as compared to Asian Xoo (Gonzalez et al. 2007; Tekete et al. 2020). Race profiling on near isogenic lines (NILs) reported the potential of $X a 4, x a 5$ and $X a 7$ or co-segregating genes to control a few African Xoo from Burkina Faso, Niger, and Cameroon (Gonzalez et al. 2007), but the resistance spectrum of these genes has yet to be evaluated on a larger set of strains. Furthermore, $\mathrm{Xa1}$ comes up as one of the most promising $R$ genes in terms of resistance spectrum for the Malian Xoo population (Tekete et al. 2020). Other studies to identify resistance against African Xoo evaluated 107 accessions of O. glaberrima, the cultivated rice species domesticated in Africa, as well as improved varieties including NERICA (NEw RICe for Africa) (Djedatin et al. 2011; Wonni et al. 2016). NERICA varieties are often the result of the inter-specific crosses between O. glaberrima, which represents important germplasm for resistance to local biotic and abiotic stresses, and high-yielding Asian O. sativa. These studies identified 25 accessions of $O$. glaberrima that are resistant to one or more African strains of Xoo, and five Burkinabe elite rice varieties (Djedatin et al. 2011; Wonni et al. 2016). Genes or quantitative trait loci accounting for resistance in these varieties remain to be explored.

In this study, toward providing breeders with new resistance genes against African Xoo, we screened 86 rice accessions including 16 accessions tested previously (Djedatin et al. 2011; Wonni et al. 2016) for resistance to two reference African Xoo strains MAI1 and BAI3, respectively originating from Mali and Burkina Faso. We included the Asian strain $\mathrm{PXO} 99^{\mathrm{A}}$ for comparison. For select accessions, we probed with individual TALEs from the African strains expressed in PXO99 ${ }^{\mathrm{A}}$ to identify potential $E$ or other TALE-dependent resistance genes. We report on the identification of 12 accessions showing resistance to both African strains, nine of which involving an Xa1-like immunity, and unveil two TALEs with avirulence activity in African Xoo. Interestingly, our approach unmasked the occurrence of two overlapping TALE-mediated sources of resistance in the rice variety CT13432, one involving Xa1-like activity and the other a so far unknown TalI-dependent $E$ gene.

\section{Results}

Germplasm Screening for TALE-Dependent Resistance Against African Xoo Uncovers Three Resistant Rice Varieties To search for African Xoo tales with avr activity, we established a gain-of-function approach consisting in the trans-expression of these tal genes in a virulent recipient strain of Xoo. We first screened a germplasm of 86 accessions of rice and selected those that were susceptible to the Asian Xoo strain PXO99 ${ }^{\mathrm{A}}$ and resistant to the reference African Xoo strains MAI1 and BAI3.
Twelve accessions exhibited that phenotype, including two O. glaberrima, seven O. sativa (two indica and one japonica), and three elite varieties that are popular in West-Africa (Additional file 6: Table S1). To investigate whether the resistance of these 12 accessions to African Xoo is triggered by TALEs, each of the nine tal genes of the Xoo strain MAI1 was introduced into the virulent strain PXO99 ${ }^{\mathrm{A}}$. The expression in PXO99 ${ }^{\mathrm{A}}$ of each TALE was confirmed by Western blot (Additional file 1: Fig. S1). Each PXO99 ${ }^{\mathrm{A}}$ transformant carrying an Xoo MAI1 tal gene was inoculated to the 12 accessions and to the rice variety Azucena, which was used as susceptible check. No significant difference in lesion lengths was observed upon leaf-clip inoculation of Azucena leaves with the different transformants 15 days after inoculation. In contrast, the varieties CT13432 and FKR47N exhibited resistance when inoculated with $\mathrm{PXO} 99^{\mathrm{A}}$ transformants carrying tall and talF, respectively. In addition, $\mathrm{PXO}^{\mathrm{A}}$ strains with talD or talH both elicited resistance when inoculated to the O. sativa ssp. indica variety IR64. Overall, four TALEs with avirulence activity and three rice accessions with TAL-dependent resistance were pinpointed through this gain-of-function strategy (Table 1).

\section{Genes Mutagenesis Confirms talD Avirulence Activity in IR64}

To confirm that talD, talH, tall and talF act as avirulence genes in strain MAI1, we attempted to generate a library of MAI1 tal gene mutants by transformation of the suicide plasmid pSM7 as reported previously (Cernadas et al. 2014; Tran et al. 2018). Because MAI1 turned out to be poorly amenable to genetic transformation, we focused on the Xoo strain BAI3, which has a similar TALome (Tran et al. 2018). We obtained at least one mutant strain with a single insertion for each tal gene, except for talH (Additional file 2: Fig. S2). Alongside wild-type (WT) BAI3, mutant strains BAI $3 \Delta$ tall, BAI $3 \Delta$ talF and BAI $3 \Delta$ talD were inoculated to CT13432, FKR47N and IR64, respectively, and to the Azucena susceptible control. Both leaf-clip inoculation and leaf-infiltration of the three BAI3 $\Delta$ tal mutants produced WT-like symptoms on Azucena, indicating that virulence of these mutant strains was not affected (Fig. 1; Additional file 3: Fig. S3). In contrast, an increase of lesion lengths was observed upon clip-inoculation of leaves of IR64 with BAI3 $\Delta$ talD. Avirulence was fully restored when a plasmid-borne copy of talD was introduced into BAI $3 \Delta$ talD (Fig. 1A), demonstrating the avirulence activity of talD in IR64. In contrast, no loss of resistance was observed upon leaf-infiltration or leaf-clipping of CT13432 and FKR47N with talI or talF mutant strains, respectively (Additional file 3: Fig. S3, Fig. 1B), leading to the hypothesis that one or more other avr activities, corresponding 
Table 1 Four African TALEs mediate resistance when expressed in PXO99A on resistant varieties

\begin{tabular}{|c|c|c|c|c|c|}
\hline Name & Species & MAI1 $^{\circ}$ & $\mathrm{BAI}^{\circ}$ & PXO99 Ao & $\begin{array}{l}{ }^{*} \text { Candidate } \\
\text { avirulence TALEs }\end{array}$ \\
\hline Og_107 & O.glaberrima & $\mathrm{R}$ & MR & $S$ & - \\
\hline Og_162 & O. glaberrima & $\mathrm{R}$ & MR & S & - \\
\hline WAB56-50 & O. sativa ssp. japonica & $\mathrm{R}$ & $\mathrm{R}$ & S & - \\
\hline WAB181-18 & O. sativa ssp. japonica & $\mathrm{R}$ & $\mathrm{R}$ & S & - \\
\hline FKR19 & O. sativa ssp. japonica & $\mathrm{R}$ & $\mathrm{R}$ & S & - \\
\hline FKR43 & O. sativa ssp. japonica & $\mathrm{R}$ & $\mathrm{R}$ & S & - \\
\hline IR64 & O. sativa ssp. indica & $\mathrm{R}$ & MR & S & TalD, TalH \\
\hline CT13432 & O. sativa ssp. japonica & $\mathrm{R}$ & $\mathrm{R}$ & S & Tall \\
\hline Gigante & O. sativa & $\mathrm{R}$ & $\mathrm{R}$ & S & - \\
\hline FKR45N & O. sativa ssp. japonica / O. glaberrima & $\mathrm{R}$ & $\mathrm{R}$ & S & - \\
\hline FKR47N & O. sativa ssp. japonica / O. glaberrima & $\mathrm{R}$ & $\mathrm{R}$ & S & TalF \\
\hline FKR49N & O. sativa ssp. japonica / O. glaberrima & $\mathrm{R}$ & $\mathrm{R}$ & S & - \\
\hline Azucena & O. sativa ssp. japonica & $\mathrm{S}$ & $S$ & $S$ & - \\
\hline
\end{tabular}

${ }^{\circ}$ Resistance or susceptibility of rice to Xoo is expressed as a result of lesion length measurements 15 days after inoculation. Resistant (R), $x<5 \mathrm{~cm}$; moderately resistant (MR), $5 \mathrm{~cm}<\mathrm{x}<10 \mathrm{~cm}$; moderately susceptible (MS), $10 \mathrm{~cm}<\mathrm{x}<15 \mathrm{~cm}$; susceptible (S), $x>15 \mathrm{~cm}$

*Rice accessions were inoculated with PXO99A carrying each of the nine tal genes of MAI1. (-) means no candidate avirulence TALE identified

to one or more other $R$ genes, may be masking those of tall and talF.

\section{CT13432 and FKR47N Exhibit Xa1-Like Resistance}

When leaves of CT13432 and FKR47N were infiltrated with BAI3, an early and strong hypersensitive response (HR) apparent as rapidly developing necrosis could be observed at the site of inoculation (Additional file 3: Fig. S3). Xa1/Xo1 being able to confer resistance against African strains of Xoo and Xoc specifically (Ji et al. 2016; Triplett et al. 2016), and among the $X a$ genes that trigger an early and strong HR-like phenotype upon Xoo leaf-infiltration, we hypothesized that some $\mathrm{Xa1/Xo1-}$ like mechanism may be at play in the BAI3-CT13432/ FKR47N interactions, redundant to the talI and talFspecific resistances observed in the gain-of-function experiments. To test this hypothesis we infiltrated the Asian Xoc strain BLS256 which carries the truncTALE tal2h, and the derivative mutant strain BLS256 $\Delta$ tal $2 h$, into leaves of CT13432, FKR47N and the susceptible control Azucena (Fig. 2). As expected, all strains promoted water-soaking symptoms upon infiltration of the susceptible variety Azucena. Typical BLS symptoms were observed when leaves of CT13432 and FKR47N were infiltrated with Xoc strain BLS256, while a strong resistance phenotype appeared upon infiltration of the truncTALE derivative mutant BLS256 $\Delta$ tal $2 h$, indicating that CT13432 and FKR47N have Xa1/Xo1-like activity. To further confirm that the resistance of these varieties against Xoo strains BAI3 and MAI1 is conferred in part by an Xa1-like gene, both strains were transformed with tal $2 h$ and pathogenicity assays were performed. As expected, expression of the truncTALE in BAI3 and MAI1 resulted in a complete loss of HR on CT13432 and FKR47N, which was not the case when the strains carried an empty vector (Fig. 2). Altogether, our results suggest that African Xoo resistance in CT13432 and FKR $47 \mathrm{~N}$ is mediated by $\mathrm{Xa} 1$ or other alleles, in addition to as yet unidentified resistance genes corresponding to tall and talF.

To test whether any of the ten remaining resistant accessions involve similar mechanisms, 3-week-old plants were inoculated by infiltration and checked for appearance of the HR. As expected, Carolina Gold Select and IRBB1, carrying respectively $X o 1$ and $X a 1$, displayed water-soaking lesions when infiltrated with the Asian Xoc strain BLS256, and HR when infiltrated with the African Xoo strain BAI3 and the truncTALE derivative mutant BLS256 $\Delta$ tal2h (Additional file 4: Fig. S4). Surprisingly, seven out of the eight $O$. sativa spp. accessions also exhibited a typical Xa1-like HR to BAI3 and BLS256 $\Delta$ tal2h while being susceptible to BLS256 (and to PXO99A ${ }^{\mathrm{A}}$, which also carries iTALEs). The two O. glaberrima accessions exhibited no Xa1-like resistance, developing water-soaking in response to BAI3 or BLS256 $\Delta$ tal $2 h$ following leaf infiltration (Additional file 4: Fig. S4, Additional file 6: Table S2). Overall, these observations show that 9 of the 12 resistant varieties including CT13432 and FKR47N resist African Xoo through Xa1/Xo1-like mechanisms. 


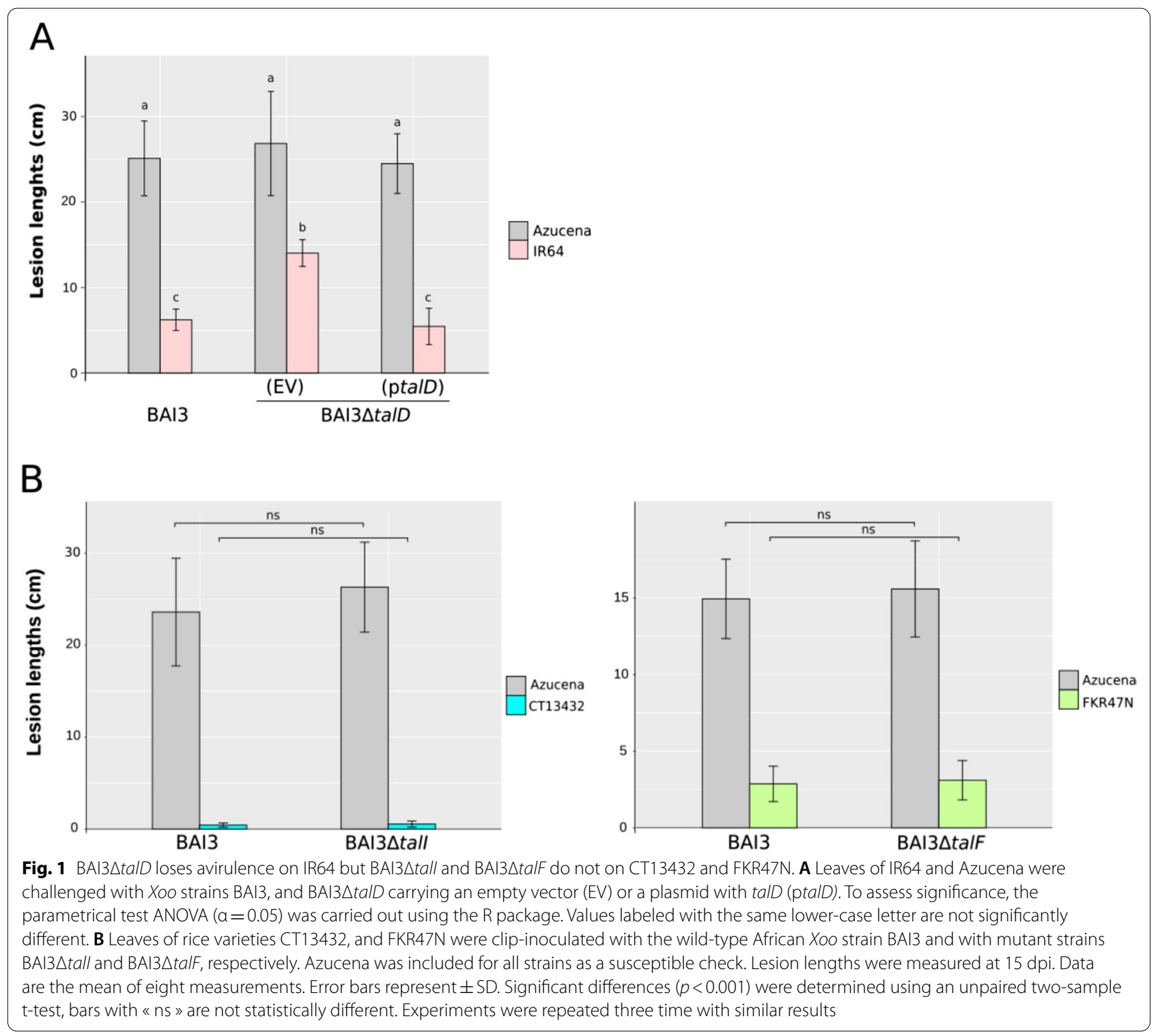

\section{Presence of $\mathrm{Xa1}$ Allelic $R$ Genes in CT13432 and FKR47N Rice Varieties}

To test the prediction that an $\mathrm{Xa1}$ allele was present in CT13432 and FKR47N, we PCR-amplified a 202 bp fragment spanning the junction of the first repeat and its up-stream region (Ji et al. 2020); Additional file 6: Table S3), allowing the discrimination of resistant and susceptible alleles (susceptible alleles yield no product). Analysis was performed also on the Xa1-carrying near-isogenic line IRBB1 and the Xo1-carrying Carolina Gold Select rice variety as positive controls, and on Azucena, Nipponbare, IR24 and IR64 as negative controls (Additional file 4: Fig. S4). Both CT13432 and
FKR47N yielded a product that co-migrated with those of the positive controls (Fig. 3A). No amplification was evident from the negative control varieties. We next tried to determine the number of leucine-rich repeats (LRRs) encoded by the CT13432 and FKR47N alleles by amplifying the LRR domain. As expected, IRBB1 and Carolina Gold yielded products of sizes consistent with the six and five LRRs of Xa1 and Xo1, respectively. CT13432 and FKR47N produced amplicons of sizes consistent with the presence of seven and six LRRs, respectively (Fig. 3B). Altogether, these results provide strong evidence that CT13432 and FKR47N varieties each carry a different allele of the $X a 1 R$ gene that is active against African Xoo strains MAI1 and BAI3. 


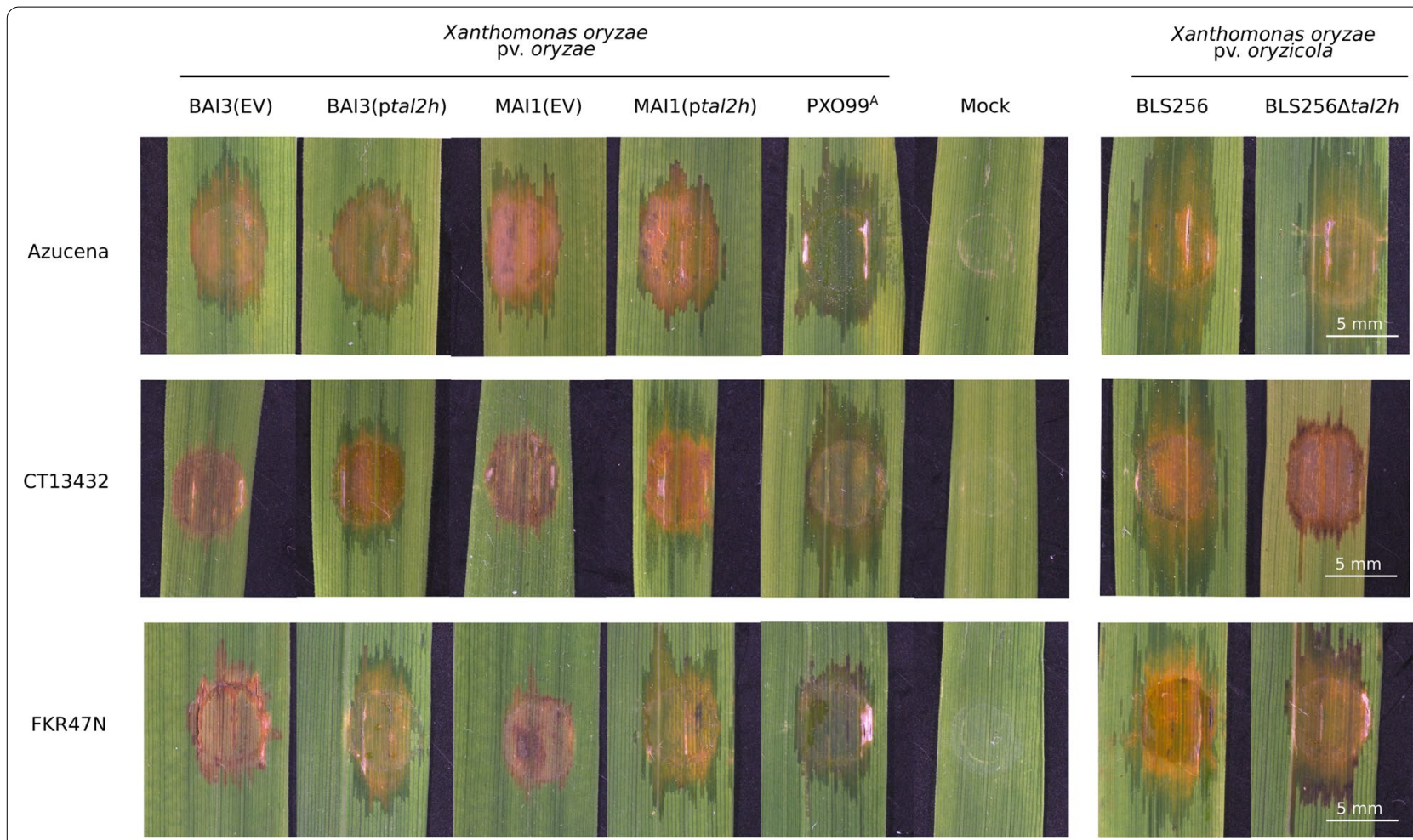

Fig. 2 The resistance of CT13432 and FKR47N against African Xoo is largely suppressed by a truncTALE. Leaves of CT13432 and FKR47N rice varieties were inoculated with Xoo strains BAl3 and MAl1 carrying an empty vector (EV) or the truncTALE tal2h as well as Xanthomonas oryzae pv. oryzicola (Xoc) strain BLS256 which is naturally carrying tal2h and the mutant strain BLS256 $\triangle t a l 2 h$. The susceptible rice variety Azucena and the Asian XoO strain $\mathrm{PXO99^{A }}$ were used as controls. Leaves were photographed at $5 \mathrm{dpi}$

\section{Suppression of the Xa1-Like Resistance in CT13432 Unmasks an Underlying Tall Activation Domain-Dependent Resistance}

We hypothesized that the Xa1-like resistance in CT13432 and FKR47N explains the failure of the talI and talF knockouts in BAI3 to abolish avirulence of the mutants, respectively, on these varieties (Fig. 1A). To test this hypothesis directly, we first introduced a plasmid-borne copy of tal $2 h$ into BAI3 and inoculated to CT13432 and the susceptible variety Azucena. The presence of tal $2 \mathrm{~h}$ indeed suppressed the Xa1-like resistance to BAI3 in CT13432, resulting in moderate disease symptoms development (Fig. 4A), and higher bacterial titers in planta (Fig. 4B) as compared with a BAI3 empty vector control. We next tested whether the combination of tal $2 h$-mediated Xal-like suppression and talI inactivation would lead to even higher virulence on CT13432 by introducing tal2h (or the empty vector) into BAI $3 \Delta$ talI(ptal2h). No significant differences in lesion lengths or bacterial populations were observed between BAI3(ptal2h) and BAI3 $\Delta$ talI(ptal $2 h$ ) $(\mathrm{EV})$. However, expression of $\mathrm{talI}_{B A I 3}$ in trans in BAI3 $\Delta$ talI $(\mathrm{ptal} 2 h)$ dramatically reduced lesion lengths and bacterial titer in planta, relative to the empty vector in BAI3 $\Delta$ talI $(\mathrm{ptal} 2 h)$. These results demonstrate that talI $_{B A I 3}$ avr activity in CT13432 can be detected when Xa1 is inactivated. We next evaluated if restoration of avirulence could also be obtained upon expression of talI $_{M A I 1}$ which is polymorphic at RVDs 4 and 9 (Tran et al. 2018). As with talI $_{B A I 3}$, expression of talIMAI1 leads to reduced lesion lengths and in planta bacterial amounts, indicating that both talI variants confer avirulence on CT13432 (Fig. 4). We next evaluated the requirement of the activation domain (AD) in the talIspecific resistance. BAI $3 \Delta \operatorname{tal}(\mathrm{ptal} 2 h$ ) transformed with the deletion derivative construct ptalI ${ }_{M A I 1} \Delta \mathrm{AD}$ failed to trigger resistance in CT13432 while it remained fully virulent on the susceptible variety Azucena (Fig. 4A). Western-blot analysis verified that TalI MAI1 $_{1}$ and TalI $_{\text {MAI1 }} \Delta \mathrm{AD}$ accumulate at comparable levels (Additional file 5: Fig. S5). Altogether our results show that the TalI specifically elicits a form of resistance distinct from the Xa1-like resistance in CT13432 and that this elicitation relies on the activation domain of TalI, suggesting the presence of a TalI-activated $E$ gene. Further analysis will be necessary to elucidate whether the same is true for talF-mediated resistance in FKR47N. 


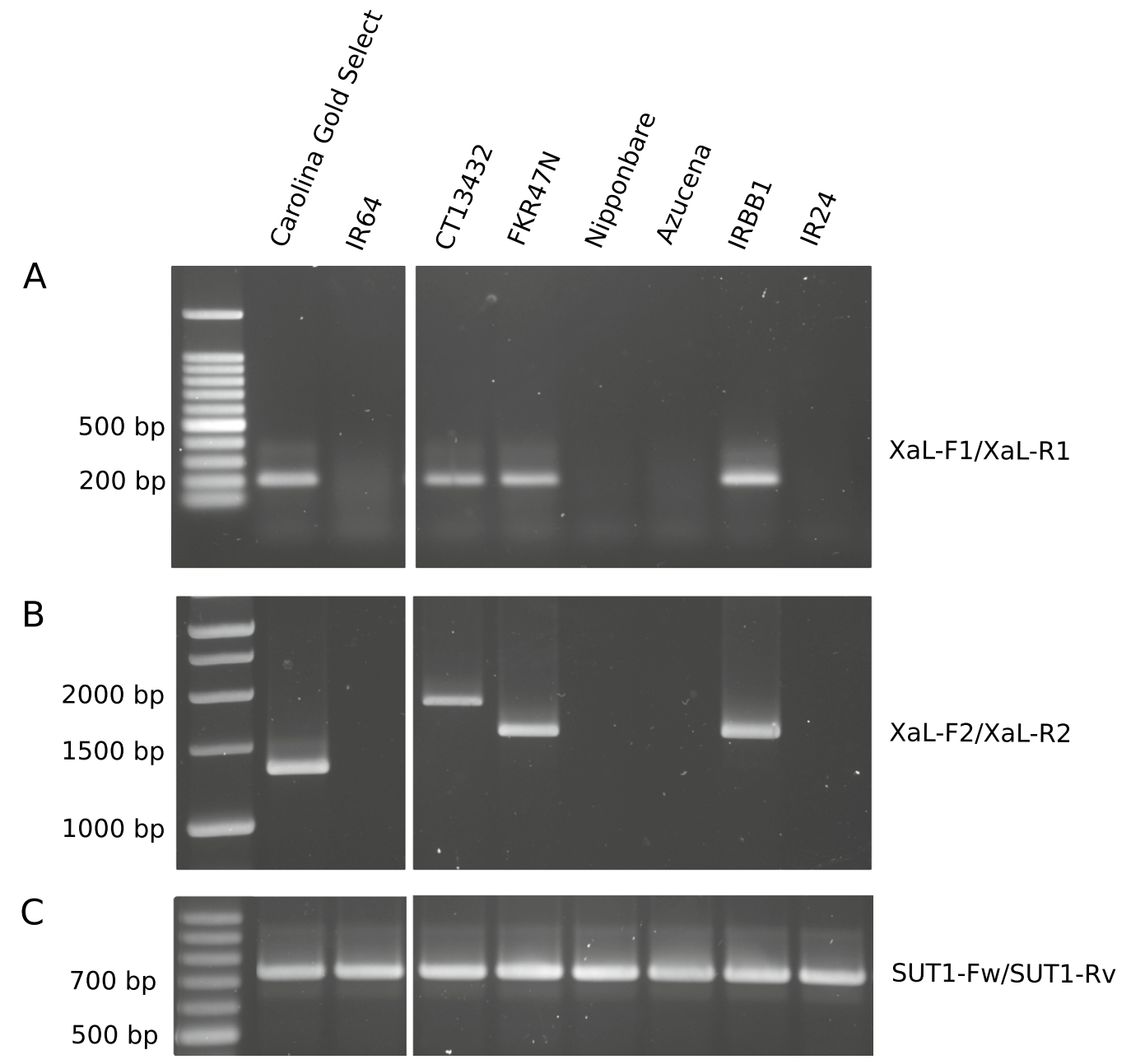

Fig. 3 The rice varieties CT13432 and FKR47N carry distinct apparent alleles of Xa1. The genomic DNA of rice varieties Carolina Gold Select, IR64, CT13432, FKR47N, Nipponbare, Azucena, IRBB1 and IR24 were used as a template for PCR amplification of $\mathbf{A}$ the junction of the first repeat of 279 base pairs of $\mathrm{Xa}$ 1 and its upstream region, $\mathbf{B}$ the whole repeat region of $\mathrm{Xa} 1$ and alleles, and $\mathbf{C}$ the housekeeping gene OsSUT1 used as a control. All the samples were run on the same gel

\section{Discussion}

First identified in Japan in 1884, BLB has been long recognized as a major threat in many Asian countries, and therefore for decades at the heart of many research and resistance breeding programs (Liu et al. 2014). To date, a handful of avirulence genes have been cloned from Asian Xoo strains, all of which encode TAL effectors including avrXa7, avrXa10, avrXa23, and avrXa27 (Hopkins et al. 1992; Gu et al. 2005; Wang et al. 2014). In contrast, no avirulence gene has been identified in African Xoo strains, the first of which were isolated in the 1980s. However, as many as nine races of African strains, not found among Asian strains, have been reported so far (Gonzalez et al. 2007; Tekete et al. 2020), indicating that some effector genes of African Xoo strains act as avirulence factors in gene-for-gene interactions with some rice $R$ genes. Comparison between African and Asian Xoo TALomes shows that no tal gene is conserved between these two Xoo lineages (Lang et al. 2019). Strains of both lineages induce the $S$ genes OsSWEET14 and OsTFX1 through unrelated TALEs, highlighting cases of inter-lineage evolutionary convergence of virulence functions (Streubel et al. 2013; Tran et al. 2018). In contrast, none of the rice $E$ genes induced by Asian Xoo is predicted to be targeted by any African Xoo TALE. Here, toward identifying sources of resistance effective against African Xoo strains, we assessed the putative $a v r$ activity of 12 previously cloned individual tal genes representing the TALome of two African Xoo strains (Tran et al. 2018), using a large set of rice accessions. 

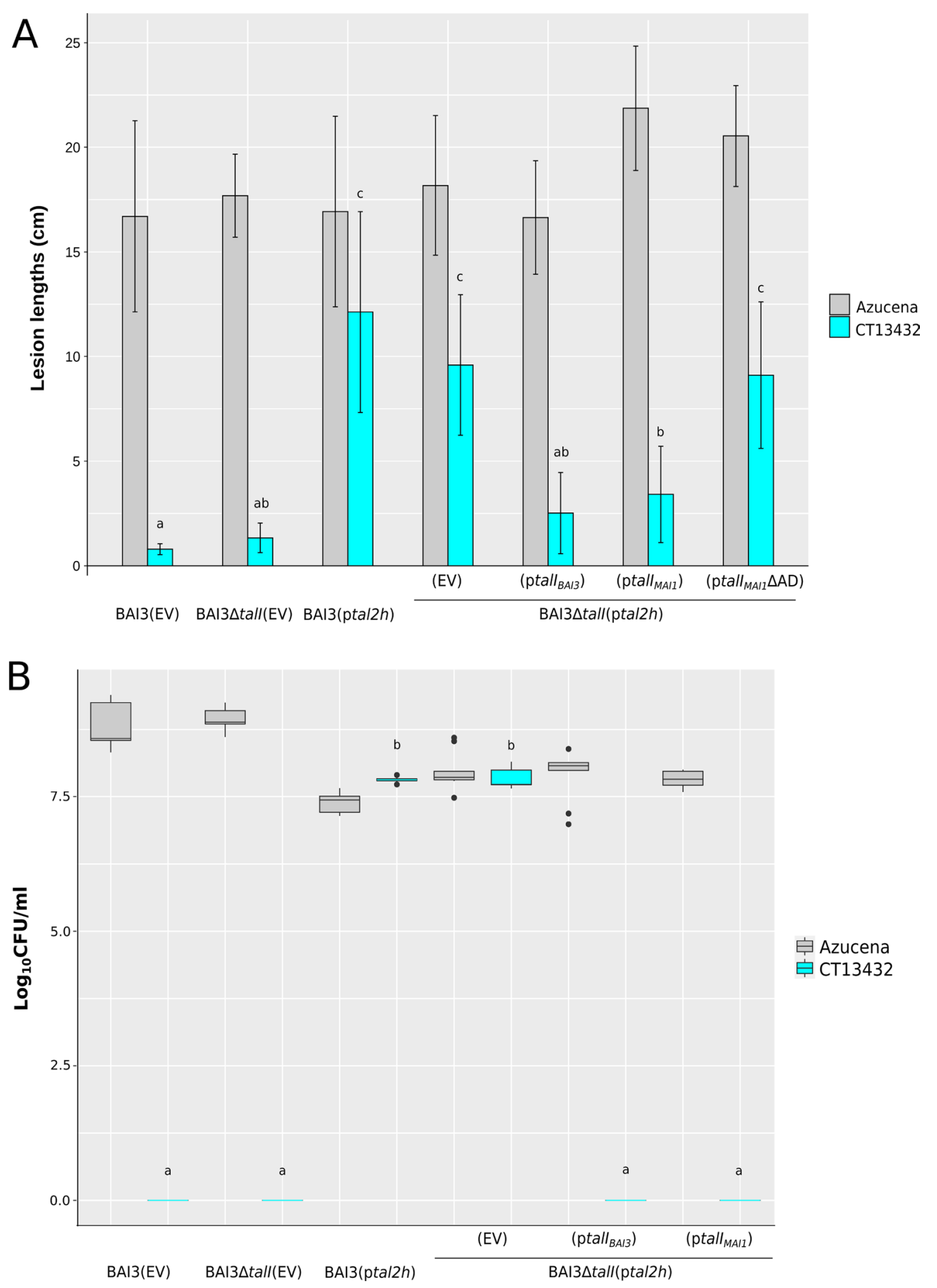

Fig. 4 Suppression of Xa1-like resistance unmasks Tall avirulence activity in the rice variety CT13432. A Leaves of CT13432 and Azucena plants were clip-inoculated with the Xoo strain BAI3 carrying the pKEB31 empty vector (EV), the BAl3 $\triangle$ tall mutant carrying the pKEB31 empty vector (EV), the

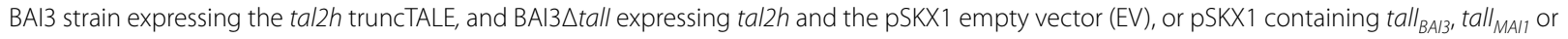
tall $_{\text {MAI }} \triangle \mathrm{AD}$. Lesion lengths were measured at $15 \mathrm{dpi}$. Data are the mean of eight measurements. B Bacterial counts were taken $7 \mathrm{dpi}$ of rice leaves of CT13432 and Azucena inoculated with the same panel of Xoo strains used in (A). Statistical tests in both experiments were carried out in R using the nonparametric Kruskal-Wallis and Dunn's tests $(a=0.05)$. Values labeled with the same lower-case letter are not significantly different 
To accomplish this goal, we first took a gain-of-function approach using the virulent Asian Xoo strain PXO99 ${ }^{\mathrm{A}}$ as a recipient to express cloned African tal genes. In a similar approach, we previously identified major virulence TALEs of African Xoo strains using the US strain Xo X11-5A as recipient (Tran et al. 2018). X11-5A lacks tal genes and is weakly virulent, allowing for gain-of-virulence screening (Ryba-White et al. 1995; Triplett et al. 2011). Nonetheless in a search for gain-of-avirulence, the use of a more virulent strain is required. By selecting the Asian strain PXO99 ${ }^{\mathrm{A}}$ as recipient, we also minimized the risk of TALE functional redundancy. This strategy led to the identification of talI and talF respectively causing resistance in rice varieties CT13432 and FKR47N, as well as talD and talH, each triggering resistance on IR64.

In a complementary approach, a loss-of-function analysis was carried out by mutagenizing individual tal genes in the African Xoo strain BAI3. This analysis validated talD and tall as avirulence genes; a mutant for talH was not obtained. Because IR64 has been sequenced and recombinant populations are available (Fragoso et al. 2017), prospects for future identification of the gene(s) underlying the TalD-elicited resistance are good. Mutagenesis of tall or talF failed to cause a measurable loss of avirulence in the respective rice varieties CT13432 and FKR47N. However, tall avirulence activity was evident upon trans-expression of the truncTALE tal $2 h$ in $\mathrm{BAI} 3 \Delta$ tall, revealing that a resistance like that mediated by $\mathrm{Xa} 1$ in response to TALEs generally and suppressed by truncTALEs, is present in CT13432 and masking the TalI-specific resistance. By further taking advantage of this combined gain- and loss-of-function approach, we also determined that the TalI-specific resistance depends on the activation domain of the effector and thus likely involves an $E$ gene.

While four TALE groups including TalG, TalE, TalD and TalC are strictly conserved between Xoo strains MAI1 and BAI3, two to six RVD variations were reported in the five other groups, modifying to some extent their DNA binding sequence specificities (Tran et al. 2018). Notably, three of the four candidates or validated avirulence TALEs identified in this study, TalI, TalF, and TalH all present RVD polymorphisms across Malian and Burkinabe strains, which could be the result of some ongoing selection pressure imposed by corresponding $E$ or other resistance genes (Doucouré et al. 2018; Schandry et al. 2018). Surprisingly, the TalD group is much more conserved, highlighted by an absolute RVD conservation between BAI3, MAI1 and the Cameroonian strain CFBP1947 (Tran et al. 2018), and only one polymorphic RVD among nine Malian strains investigated (Doucouré et al. 2018). According to the EBE prediction tools Target Finder and Talvez (Doyle et al. 2012; Pérez-Quintero et al.
2013), $90 \%$ of the first 20 predicted targets of the two versions of TalD are conserved. Such a conservation among strains hints to an important role in virulence for TalD, but there are no data supporting this hypothesis so far. Concerning the TalI group, BAI3 and MAI1 alleles differ at two RVDs and share about $32 \%$ of their predicted targets, querying the Nipponbare genome. Since both variants equally elicit resistance in the rice variety CT13432, their polymorphism may confer an advantage in future identification of the putative corresponding $E$ gene; the gene is likely to reside among the relatively smaller number of predicted targets in that genome that are shared by the two alleles.

Up to now $12 R$ genes against BLB have been cloned, of which 9 are triggered by TALEs (Jiang et al. 2020; Chen et al. 2021; Luo et al. 2021). This proportion not only highlights the crucial role of this effector family in the rice-Xoo pathosystem but also the relevance of using TALEs as probes to identify resistance sources and clone the underlying genes. This quest is facilitated by the ability to identify candidate targets of TALEs by combining EBE prediction and expression analysis, owing to the modular nature of TALE DNA interactions and their strong transcriptional upregulation of targets (Boch et al. 2014). In a proof-of-concept study pioneering this strategy for $E$ gene identification, Strauss et al. (2012) identified the pepper $B s 4 C$ gene, which is specifically induced by the TALE AvrBs4 from X. euvesicatoria. More recently, a mix of map-based cloning and EBE predictions led to the isolation of the $E$ gene $\mathrm{Xa}$ 7 in rice, which is triggered by the Xoo TALE AvrXa7 (Chen et al. 2021; Luo et al. 2021). In our study, out of the 86 accessions phenotyped, 12 were found to be resistant to both African Xoo strains MAI1 and BAI3, including 7 accessions of O. sativa, 2 of O. glaberrima and 3 NERICAs. Moreover, 12 O. glaberrima, 3 O. sativa, 3 O. barthii and 2 NERICA accessions were discovered to be resistant specifically to the Malian strain MAI1.

Among the 12 accessions identified as resistant to Xoo African strains MAI1 and BAI3, 9 accessions, including CT13432 and FKR47N, showed a phenotype typical of $\mathrm{Xa1}$ resistance (Additional file 6: Table S2; Additional file 4: Fig. S4). This is not surprising since Xa1 and its functional homologs exhibit broad-spectrum resistance against African Xoo specifically, owing to the lack of iTALEs in examined African Xoo strains (Ji et al. 2016; Read et al. 2016). The $X a 1$ allele that we discovered in the rice variety CT13432 appears to contain seven LRRs, like the allele originally identified as $X a 45(t)$, which was cloned from the wild rice variety Oryza nivara-1 (Ji et al. 2020). Other alleles reported to date contain 4 (Xa14), 5 (Xa2 and Xo1), and 6 repeats (Xa1). Variety FKR47N contains an allele that appears to have 6 LRRs. FKR47N, 
also called NERICA 17, is the result of crossing $O$. glaberrima variety CG14 and O. sativa ssp. japonica variety WAB181-18, backcrossing to WAB181-18 as recurrent parent. Xa1 alleles have been reported in other NERICAs. Alleles in NERICAs 5 and 7, the recurrent parent of which is the O. sativa ssp. japonica rice variety WAB56104, have five and six LRRs respectively. NERICAs 12 and 14 , coming from the O. sativa ssp. japonica rice variety WAB56-50, each carry an allele with five LRRs (Ji et al. 2020). According to Ji et al. (2020), a search for Xa1 allelic members in the 3000 rice genomes revealed that approximately $15 \%$ contain the Xa1 signature sequence. A phenotypic screening for $\mathrm{Xa1}$-like resistance in 87 rice accessions revealed its presence in 16 of them, including different rice species such as $O$. glaberrima, O. nivara and O. sativa (Ji et al. 2020). A complementary study on more than $500 \mathrm{O}$. sativa accessions revealed that Xa1 alleles were present in aus, indica, temperate and tropical japonica (Zhang et al. 2020). The frequency of $\mathrm{Xa1}$ alleles among diverse rice varieties and the variability of LRRs number among $\mathrm{Xa} 1$ alleles observed in these studies and revealed further by our results, underscores the unanswered question of the origin of the gene and the drivers of its diversification.

BLB represents a serious threat to rice production in Africa. Varietal resistance is the best strategy to control BLB durably, but it requires sources of resistance effective against the local pathogen genotypes. So far, no African strain of Xoo with iTALE/truncTALE has been identified, which makes $\mathrm{Xa} 1$ and its alleles promising tools to control BLB in Africa. Although the durability of $\mathrm{Xa1}$ in Africa is difficult to predict, the risk of emergence of strains of Xoo originating from Asia and their spread through the African continent seems high in the current context of intense global exchanges of rice germplasm and insufficient phytosanitary measures. Pyramiding of resistance genes against BLB is of great value to extend the durability and the spectrum of resistance within a rice variety (Oliva et al. 2019). CT13432 combines several rice blast resistance genes (Pi1, Pi2 and Pi33) (Tharreau et al. 2007; Utami et al. 2011), but here we found out that it also carries at least two, distinct types of resistance to BLB, an apparent Xa1 allele and a putative, TalI-dependent $E$ gene, making it an excellent material for breeding to create improved varieties for Africa. What is more, we expect that CT13432 might also carry yet another blast resistance gene, Pi63, which resides at the same locus as Xo1 in Carolina Gold Select (Read et al. 2020b).

\section{Conclusions}

In this study, we identified 12 rice accessions exhibiting resistance against African strains of Xoo and described 4 TAL effectors from these strains that exhibit avirulence activity. Analysis of the mechanisms underlying the resistance of the rice variety CT13432 revealed the occurrence of two overlapping sources of resistance including an apparent allele of the broad-spectrum resistance gene $X a 1$ and an unidentified putative $E$ gene that is activated by TalI. Combining transcriptomics and EBE prediction tools in the genome of CT13432 may allow discovery of this gene in the future. This approach would also be useful to decipher what genes in IR64 confer resistance against strains of Xoo with TalD.

\section{Material and Methods}

\section{Bacterial Strains and Growth Conditions}

Bacterial strains used in this study are listed in Additional file 6: Table S4. Escherichia coli was cultivated at $37^{\circ} \mathrm{C}$ in liquid or solid (15 g agar per L) Luria-Bertani (LB) medium (10 $\mathrm{g}$ of tryptone, $5 \mathrm{~g}$ of yeast extract, and $5 \mathrm{~g}$ of $\mathrm{NaCl}$ per L of distilled water), and Xanthomonas oryzae pathovars at $28{ }^{\circ} \mathrm{C}$ in liquid or solid (16 g agar per L) peptone sucrose medium (10 g of peptone, $10 \mathrm{~g}$ of sucrose, and $1 \mathrm{~g}$ of glutamic acid per $\mathrm{L}$ of distilled water).

\section{Plant Materials and Plant Inoculations}

The rice accessions screened in this study are listed in Additional file 6: Table S1. Plants used were grown in a greenhouse under cycles of $12 \mathrm{~h}$ of light at $28^{\circ} \mathrm{C}$ with $80 \%$ relative humidity (RH) and $12 \mathrm{~h}$ of dark at $25^{\circ} \mathrm{C}$ with $70 \% \mathrm{RH}$. When used for bacterial quantification assays, plants were grown in a growth chamber at $28{ }^{\circ} \mathrm{C}$ and $80 \%$ RH (day and night). For lesion length assays, leaves of 5 -week-old plants were inoculated by leaf-clipping with a bacterial suspension at an optical density at $600 \mathrm{~nm}$ $\left(\mathrm{OD}_{600}\right)$ of 0.2. Lesion lengths were measured 15 days post inoculation (dpi) on at least eight leaves from individual plants per experiment. Leaves of 3-week-old plants were infiltrated with a needleless syringe and a bacterial suspension at an $\mathrm{OD}_{600}$ of 0.5. Symptoms were photographed at $5 \mathrm{dpi}$. For bacterial quantification assay, 5-week-old plants were inoculated by leaf-clipping and $10 \mathrm{~cm}$ distal leaf fragments of three leaves from three individual plants per condition were cut in half and ground in liquid nitrogen separately as reported previously (Yu et al. 2011).

\section{Plasmid Transformation}

Plasmids were introduced into E. coli cells by heat-shock transformation and into Xoo by electroporation or triparental mating (Figurski and Helinski 1979). Appropriate antibiotics for selection were added to growth media at the following final concentrations: rifampicin, $100 \mu \mathrm{g} \mathrm{ml}{ }^{-1}$; gentamicin, $100 \mu \mathrm{g} \mathrm{ml}{ }^{-1}$; tetracycline, $100 \mu \mathrm{g} \mathrm{ml}^{-1}$; kanamycin, $100 \mu \mathrm{g} \mathrm{ml}^{-1}$. 
tal genes of the African Xoo strains MAI1 and BAI3 are cloned in pSKX1, which confers gentamicin resistance (Tran et al. 2018; Additional file 6: Table S4). The truncTALE tal $h$ is cloned in pKEB31, which confers tetracycline resistance (Read et al. 2016; Additional file 6: Table S4). The plasmids are compatible with each other.

\section{Mutant Library Construction and Characterization}

The BAI3 $\Delta$ tal mutants were generated upon electroporation of the wild-type strain BAI3 with the suicide plasmid pSM7 (Cernadas et al. 2014). Mutant strains were selected with kanamycin at $100 \mu \mathrm{g} \mathrm{ml}^{-1}$. The mutant library was characterized by Southern blot analysis. Extraction of Xoo genomic DNA (gDNA) was performed using the Wizard Genomic DNA Purification kit (Promega ${ }^{\circledR}$ ). Four micrograms of gDNA were digested by BamHI-HF (New England Biolabs) at $37^{\circ} \mathrm{C}$ overnight. The digested DNA was separated in a $1 \%$ agarose gel at 50 Volts for $72 \mathrm{~h}$ at $4{ }^{\circ} \mathrm{C}$ and transferred to a nylon membrane $\left(\right.$ Roche $^{\circledR}$ ) overnight. Hybridization was conducted according to the procedures described in the DIG High Prime DNA Labeling and Detection Starter kit II protocol $\left(\right.$ Roche $\left.^{\circledR}\right)$, using a 725-bp C-terminal TalC $C_{\text {MAI1 }}$ amplicon as probe (Yu et al. 2011).

\section{Construction of tall Activation Domain Mutant}

The talI $_{M A I I} \triangle \mathrm{AD}$ construct was made by swapping the central repeat region of a $t a l F_{M A I I} \triangle \mathrm{AD}$ construct with that of talI $_{\text {MAI1 }}$. To create the talF $_{M A I 1} \Delta \mathrm{AD}$ construct, a PCR product corresponding to a $520 \mathrm{bp}$ fragment encoding the $\mathrm{C}$-terminus of talF $_{\mathrm{MAI}}$ was obtained with primers $\triangle \mathrm{AD} \_F w$ and $\triangle \mathrm{AD} \_\mathrm{Rv}$ (Additional file 6: Table S3), thereby allowing to introduce an inframe $167 \mathrm{bp}$ deletion. This amplicon was introduced into pSKX1_talF $F_{\text {MAII }}$ between the PvuI and HindIII restriction sites using T4 DNA ligase (Promega ${ }^{\circledR}$ ) according to manufacturer's recommendations, creating pSKX1_talF $F_{M A I I} \triangle \mathrm{AD}$. The talI $_{M A I 1}$ central repeat region was then swapped into pSKX1_talF $F_{M A I 1} \Delta \mathrm{AD}$ using StuI and AatII (NEB, New England Biolabs) to generate pSKX1_talI ${ }_{M A I I} \Delta \mathrm{AD}$. The plasmid was confirmed by Sanger sequencing.

\section{Expression Analysis by Western Blotting}

Xoo strains carrying the different combinations of TALEencoding plasmid, truncTALE (tal $2 h$ ) -encoding plasmid, and empty vectors (pSKX1 or pKEB31) were grown in liquid peptone sucrose medium supplemented with the corresponding antibiotics at $28^{\circ} \mathrm{C}$. Cells of $1 \mathrm{ml}$ of a bacterial suspension at an $\mathrm{OD}_{600}$ of 0.4 were harvested. Proteins were extracted with the BugBuster ${ }^{\circledR}$ Master Mix (Novagen), according to manufacturer's recommendations. The total protein concentration of each sample was calculated by a Bradford assay following the Bio-Rad
Protein Assay protocol (Bio-Rad, USA), and protein concentrations adjusted. TALEs and truncTALE expression was analyzed by sodium dodecyl sulfate polyacrylamide gel electrophoresis using a 4-15\% polyacrylamide gel and immunoblotting using the anti-TALE polyclonal antibody produced by Read et al. (2016) followed by a horseradish peroxidase conjugated rabbit secondary antibody (Sigma-Aldrich). Detection was carried out using the Thermo Scientific ${ }^{\mathrm{TM}}$ Pierce ${ }^{\mathrm{TM}}$ ECL 2 Western Blotting Substrate kit and a Typhoon ${ }^{\mathrm{TM}}$ FLA 9500 (General Electric Healthcare Life Sciences, USA) for imaging.

\section{PCR-Amplification of Putative Functional Xa1 Alleles}

To identify rice accessions harboring a potentially functional $\mathrm{Xa1}$ allele and to decipher the number of 93 aa repetitions, genomic DNA of rice accessions was extracted using an adaptation of the Murray and Thompson protocol (Murray and Thompson 1980) and was subjected to PCR using pairs of primers XaL-F1/XaL-R1 and XaL-F2/ XaL-R2, respectively (Additional file 6: Table S3; Ji et al. 2020).

\section{Abbreviations}

AD: Activation Domain; Avr: Avirulence; BLB: Bacterial Leaf Blight; EBE: Effector Binding Element; E. coli: Escherichia coli; E gene: Executor gene; HR: Hypersensitive-Response; iTALE: interfering Transcription Activator-Like Effector; LB medium: Luria-Bertani medium; LRRs: Leucine-Rich-Repeats; NILs: Near Isogenic Lines; NLR: Nucleotide-binding domain leucine-rich repeat containing receptor; NERICA: NEw RICe for Africa; OD: Optical Density; O. glaberrima /O. barthii / O. sativa: Oryza glaberrima / Oryza barthii / Oryza sativa; PCR: Polymerase Chain Reaction; RH: Relative Humidity; RLK: Receptor-Like Kinase; RVD: Repeat-Variable Diresidue; R gene: Resistance gene; S gene: Susceptibility gene; SWEET: Sugars Will Eventually be Exported Transporters; TAL: Transcription Activator-Like; TALE: Transcription Activator-Like Effector; truncTALE: Truncated Transcription Activator-Like Effector; T3E:Type-3 Effectors; T3SS: Type-3 Secretion System; Xoc: Xanthomonas oryzae pv. oryzicola; Xoo: Xanthomonas oryzae pv. oryzae.

\section{Supplementary Information}

The online version contains supplementary material available at https://doi. org/10.1186/s12284-022-00553-9.

Additional file 1: Fig. S1. Western-blot of PXO99 ${ }^{A}$ Xoo transformant total protein extracts using an anti-TALE antibody. Protein extracts prepared from the wild-type Xoo strain PXO99 ${ }^{A}$ and the Xoo strain PXO99 ${ }^{A}$ carrying, on the vector PSKX1, each of the nine tal genes of the Malian strain MAl1 and their variants in the Burkinabe strain BAI3. Reference molecular weights are indicated at right. The expressed MAI1 and BAI3 TALE proteins are each indicated by a red dot. Bands of lower molecular weight not present in the wild-type PXO99A extract are degradation products of the heterologously expressed TALEs, commonly observed.

Additional file 2: Fig. S2. Molecular characterization of a library of BAl3 $\triangle$ tal mutant strains. Genomic DNA of the wild-type Xoo strain BAI3 and derivative BAI3 $\Delta t a l$ mutants were digested by $B a m H I-H F$ which cuts on either side of the central repeat region of tal genes and revealed by Southern blot using a 725-bp C-terminal tal $\mathrm{C}_{\text {MAI1 }}$ amplicon as probe (Yu et al. 2011). Individual mutants were obtained for each tal gene with the exception of $\mathrm{tal} H$. One double $\mathrm{tal} / \mathrm{G} / \mathrm{tal} \mathrm{H}$ mutant was analyzed instead.

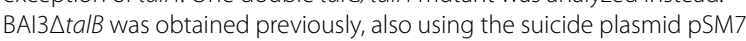


(Tran et al., 2018), and is therefore not included here. tal genes are indicated to the left and DNA sizes to the right. Red arrows indicate the tal gene(s) that were mutated.

Additional file 3: Fig. S3. Phenotypic responses upon leaf-infiltration of

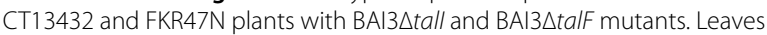
of rice varieties IR64, CT13432, FKR47N and Azucena were infiltrated with the wild type African Xoo strain BAI3 and the mutant derivatives

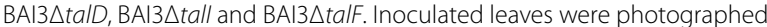
at 5 dpi.

Additional file 4: Fig. S4. The Tal2h truncTALE reveals Xa1-like resistance against the $X_{00}$ strain BAl3 in several rice varieties. Leaves of rice accessions, including Carolina Gold Select which carries Xo 1, and IRBB1 which carries Xa1, were infiltrated with Xoc strain BLS256 which naturally carries the tal2 $h$ truncTALE gene, the mutant strain BLS256 $\triangle$ tal $2 h$, as well as with Xoo strain BAl3 carrying an empty vector (EV) or tal2h. The Asian Xoo strain PXO99 ${ }^{A}$ which harbors two truncTALEs, was used as an additional positive control. Leaves were photographed at 5 dpi.

Additional file 5: Fig. S5. Western-blot analysis of Xoo total protein extracts using an anti-TALE antibody. Proteins extracts prepared from Xoo strain BAI3 carrying the empty vector pKEB31 (EV), BAI3 $\triangle$ tall carrying the empty vector pKEB31 (EV), BAI3 carrying the tal2h truncTALE gene, and BAl3 $\triangle$ tall with tal2h and the PSKX1 empty vector (EV), or pSKX1 containing tall BAI3 or tall MAII $_{\text {or tall }}$ MAII $\triangle A D$. BAl3 tal genes and tal2h are indicated to the left and right, respectively. Molecular weight is indicated.

Additional file 6. Supplemental Tables

\section{Authors' Contributions}

$\mathrm{ML}, \mathrm{BS}$, and $\mathrm{MH}$ designed the experiments. $\mathrm{ML}$ and $\mathrm{MH}$ conducted the experiments. ET participated in plant material growth and propagation. $M L, A B, B S$, and $\mathrm{MH}$ performed data analysis and wrote the manuscript. All authors read and approved the final manuscript.

\section{Funding}

This work was supported by the CRP-Rice (CGIAR Research Program) to MH and BS, and the Plant Genome Research Program of the National Science Foundation (Division of Integrative Organismal Systems IOS-1444511 to AJB).

\section{Availability of Data and Materials}

The datasets supporting the conclusions of this article are provided within the article and its Additional files.

\section{Declarations}

\section{Ethics Approval and Consent to Participate}

Not applicable.

\section{Consent for Publication}

Not applicable.

\section{Competing interests}

The authors declare that no competing interests exist.

\section{Author details}

'Plant Health Institute of Montpellier, Univ Montpellier, IRD, CIRAD, INRAE, Institut Agro, Montpellier, France. ${ }^{2}$ Plant Pathology and Plant Microbe Biology Section, School of Integrative Plant Science, Cornell University, Ithaca, NY 14853, USA.

Received: 18 October 2021 Accepted: 15 January 2022

Published online: 04 February 2022

\section{References}

Ainsworth EA (2008) Rice production in a changing climate: a meta-analysis of responses to elevated carbon dioxide and elevated ozone concentration.
Glob Chang Biol 14:1642-1650. https://doi.org/10.1111/j.1365-2486.2008. 01594.x

Boch J, Scholze H, Schornack S et al (2009) Breaking the code of DNA binding specificity of TAL-type III effectors. Science (80-) 326:1509-1512. https:// doi.org/10.1126/science.1178811

Boch J, Bonas U, Lahaye T (2014) TAL effectors—pathogen strategies and plant resistance engineering. New Phytol 204:823-832. https://doi.org/10. 1111/nph.13015

Cernadas RA, Doyle EL, Niño-Liu DO et al (2014) Code-assisted discovery of TAL effector targets in bacterial leaf streak of rice reveals contrast with bacterial blight and a novel susceptibility gene. PLoS Pathog. https://doi. org/10.1371/journal.ppat.1003972

Chen X, Liu P, Mei L et al (2021) Xa7, a new executor R gene that confers durable and broad-spectrum resistance to bacterial blight disease in rice. Plant Commun 2:100143. https://doi.org/10.1016/j.xplc.2021.100143

Chu Z, Fu B, Yang H et al (2006) Targeting xa 13, a recessive gene for bacterial blight resistance in rice. Theor Appl Genet 112:455-461. https://doi.org/ 10.1007/s00122-005-0145-6

Djedatin G, Ndjiondjop MN, Mathieu T et al (2011) Evaluation of African cultivated rice Oryza glaberrima for resistance to bacterial blight. Plant Dis 95:441-447. https://doi.org/10.1094/PDIS-08-10-0558

Doucouré H, Pérez-Quintero AL, Reshetnyak G et al (2018) Functional and genome sequence-driven characterization of tal effector gene repertoires reveals novel variants with altered specificities in closely related malian Xanthomonas oryzae pv. oryzae strains. Front Microbiol 9:1-17. https://doi.org/10.3389/fmicb.2018.01657

Doyle EL, Booher NJ, Standage DS et al (2012) TAL effector-nucleotide targeter (TALE-NT) 2.0: tools for TAL effector design and target prediction. Nucleic Acids Res 40:W117-W122. https://doi.org/10.1093/nar/gks608

Figurski DH, Helinski DR (1979) Replication of an origin-containing derivative of plasmid RK2 dependent on a plasmid function provided in trans. Proc Natl Acad Sci 76:1648-1652. https://doi.org/10.1073/PNAS.76.4.1648

Fragoso CA, Moreno M, Wang Z, et al (2017) Genetic architecture of a rice nested association mapping population. G3 Genes|Genomes|Genetics 7:1913-1926. https://doi.org/10.1534/G3.117.041608

Garcia-Ruiz H, Szurek B, Van den Ackerveken G (2021) Stop helping pathogens: engineering plant susceptibility genes for durable resistance. Curr Opin Biotechnol 70:187-195. https://doi.org/10.1016/j.copbio.2021.05.005

Gonzalez C, Szurek B, Manceau C et al (2007) Molecular and pathotypic characterization of new Xanthomonas oryzae strains from West Africa. Mol Plant-Microbe Interact 20:534-546. https://doi.org/10.1094/ MPMI-20-5-0534

Gu K, Yang B, Tian D et al (2005) R gene expression induced by a type-III effector triggers disease resistance in rice. Nature 435:1122-1125. https://doi. org/10.1038/nature03630

Hopkins C, White F, Choi S et al (1992) Identification of a Family of Avirulence Genes from Xanthomonas oryzae pv. oryzae. Mol Plant Microbe Interact 5:451-459. https://doi.org/10.1094/MPMI-5-451

Hu K, Cao J, Zhang J et al (2017) Improvement of multiple agronomic traits by a disease resistance gene via cell wall reinforcement. Nat Plants. https:// doi.org/10.1038/nplants.2017.9

Hutin M, Sabot F, Ghesquière A et al (2015) A knowledge-based molecular screen uncovers a broad-spectrum OSSWEET14 resistance allele to bacterial blight from wild rice. Plant J 84:694-703. https://doi.org/10.1111/tpj. 13042

Ji Z, Ji C, Liu B et al (2016) Interfering TAL effectors of Xanthomonas oryzae neutralize $R$-gene-mediated plant disease resistance. Nat Commun 7:1-9. https://doi.org/10.1038/ncomms13435

$\mathrm{Ji}$ C, Ji Z, Liu B et al (2020) Xa1 allelic $R$ genes activate rice blight resistance suppressed by interfering TAL effectors. Plant Commun 1:100087. https://doi. org/10.1016/j.xplc.2020.100087

Jiang N, Yan J, Liang Y et al (2020) Resistance genes and their interactions with bacterial blight/leaf streak pathogens (Xanthomonas oryzae) in rice (Oryza sativa L.) —an updated review. Rice. https://doi.org/10.1186/ s12284-019-0358-y

Lang JM, Pérez-Quintero AL, Koebnik R et al (2019) A pathovar of Xanthomonas oryzae infecting wild grasses provides insight into the evolution of pathogenicity in rice agroecosystems. Front Plant Sci 10:507. https://doi.org/10.3389/fpls.2019.00507

Liu Q, Yuan M, Zhou Y et al (2011) A paralog of the MtN3/saliva family recessively confers race-specific resistance to Xanthomonas oryzae in rice. Plant 
Cell Environ 34:1958-1969. https://doi.org/10.1111/J.1365-3040.2011. 02391.X

Liu W, Liu J, Triplett L et al (2014) Novel insights into rice innate immunity against bacterial and fungal pathogens. Annu Rev Phytopathol 52:213241. https://doi.org/10.1146/annurev-phyto-102313-045926

Luo D, Huguet-Tapia JC, Raborn RT et al (2021) The Xa7 resistance gene guards the rice susceptibility gene SWEET14 against exploitation by the bacterial blight pathogen. Plant Commun 2:100164. https://doi.org/10.1016/j.xplc. 2021.100164

Moscou MJ, Bogdanove AJ (2009) A simple cipher governs DNA recognition by TAL effectors. Science (80-) 326:1501. https://doi.org/10.1126/science. 1178817

Murray MG, Thompson WF (1980) Rapid isolation of high molecular weight plant DNA. Nucleic Acids Res 8:4321-4326. https://doi.org/10.1093/ NAR/8.19.4321

Niño-Liu DO, Ronald PC, Bogdanove AJ (2006) Xanthomonas oryzae pathovars: model pathogens of a model crop. Mol Plant Pathol 7:303-324. https:// doi.org/10.1111/j.1364-3703.2006.00344.x

Oliva R, Ji C, Atienza-Grande G et al (2019) Broad-spectrum resistance to bacterial blight in rice using genome editing. Nat Biotechnol 37:1344-1350. https://doi.org/10.1038/s41587-019-0267-z

Pérez-Quintero AL, Rodriguez-R LM, Dereeper A et al (2013) An improved method for TAL effectors DNA-binding sites prediction reveals functional convergence in TAL repertoires of Xanthomonas oryzae Strains. PLOS ONE. https://doi.org/10.1371/journal.pone.0068464

Poulin L, Grygiel P, Magne M et al (2015) New multilocus variable-number tandem-repeat analysis tool for surveillance and local epidemiology of bacterial leaf blight and bacterial leaf streak of rice caused by Xanthomonas oryzae. Appl Environ Microbiol 81:688-698. https://doi.org/10. 1128/AEM.02768-14

Read AC, Rinaldi FC, Hutin M et al (2016) Suppression of Xo 1-mediated disease resistance in rice by a truncated, non-DNA-binding TAL effector of Xanthomonas oryzae. Front Plant Sci 7:1-14. https://doi.org/10.3389/fpls. 2016.01516

Read AC, Hutin M, Moscou MJ et al (2020a) Cloning of the rice Xo1 resistance gene and interaction of the $\mathrm{Xo}_{1}$ protein with the defense-suppressing Xanthomonas effector Tal2h. Mol Plant-Microbe Interact 33:1189-1195. https://doi.org/10.1094/MPMI-05-20-0131-SC

Read AC, Moscou MJ, Zimin AV et al (2020b) Genome assembly and characterization of a complex zfBED-NLR genecontaining disease resistance locus in Carolina Gold Select rice with Nanopore sequencing. PLOS Genet 16:e1008571. https://doi.org/10.1371/journal.pgen.1008571

Ryba-White M, Notteghem JL, Leach J (1995) Comparison of Xanthomonas oryzae pv. oryzae strains from Africa, North America, and Asia by restriction fragment length polymorphism analysis. https://agris.fao.org/agrissearch/search.do? recordID=QR9500053. Accessed 14 Aug 2021

Savary S, Willocquet L, Pethybridge SJ et al (2019) The global burden of pathogens and pests on major food crops. Nat Ecol Evol 3:430-439. https://doi. org/10.1038/s41559-018-0793-y

Schandry N, Jacobs JM, Szurek B, Perez-Quintero AL (2018) A cautionary TALE: how plant breeding may have favoured expanded TALE repertoires in Xanthomonas. Mol Plant Pathol 19:1297. https://doi.org/10.1111/MPP. 12670

Song W-YY, Wang G-LL, Chen L-LL et al (1995) A receptor kinase-like protein encoded by the rice disease resistance gene, Xa21. Science (80-) 270:1804. https://doi.org/10.1126/science.270.5243.1804

Strauss T, Van Poecke RMP, Strauß A et al (2012) RNA-seq pinpoints a Xanthomonas TAL-effector activated resistance gene in a large-crop genome. Proc Natl Acad Sci U S A 109:19480-19485. https://doi.org/10.1073/pnas. 1212415109

Streubel J, Pesce C, Hutin M et al (2013) Five phylogenetically close rice SWEET genes confer TAL effector-mediated susceptibility to Xanthomonas oryzae pv. oryzae. New Phytol 200:808-819. https://doi.org/10.1111/nph.12411

Sun X, Cao Y, Yang Z et al (2004) Xa26, a gene conferring resistance to Xanthomonas oryzae pv. oryzae in rice, encodes an LRR receptor kinase-like protein. Plant J 37:517-527. https://doi.org/10.1046/j.1365-313X.2003. 01976.x

Tekete C, Cunnac S, Doucouré H et al (2020) Characterization of new races of Xanthomonas oryzae pv. oryzae in mali informs resistance gene deployment. Phytopathology 110:267-277. https://doi.org/10.1094/ PHYTO-02-19-0070-R
Tharreau D, Notteghem JL, Morel JB, et al (2007) Developing Blast Durable Resistance By Using The Wild Rice Species, Oryza rufipogon Presentasi RUTI IV. http://perpus.biotek.lipi.go.id/perpus/index. php?p=show_detail\&id=15794\&keywords=

Tian D, Wang J, Zeng X et al (2014) The Rice TAL effector-dependent resistance protein XA10 triggers cell death and calcium depletion in the endoplasmic reticulum. Plant Cell 26:497-515. https://doi.org/10.1105/tpc.113. 119255

Tran TT, Pérez-Quintero AL, Wonni I et al (2018) Functional analysis of African Xanthomonas oryzae pv. oryzae TALomes reveals a new susceptibility gene in bacterial leaf blight of rice. PLoS Pathog 14:1-25. https://doi.org/ 10.1371/journal.ppat.1007092

Triplett LR, Hamilton JP, Buell CR et al (2011) Genomic analysis of Xanthomonas oryzae isolates from rice grown in the united states reveals substantial divergence from known X. oryzae pathovars. Appl Environ Microbiol 77:3930-3937. https://doi.org/10.1128/AEM.00028-11

Triplett LR, Cohen SP, Heffelfinger C et al (2016) A resistance locus in the American heirloom rice variety Carolina Gold Select is triggered by TAL effectors with diverse predicted targets and is effective against African strains of Xanthomonas oryzae pv. oryzicola. Plant J 87:472-483. https:// doi.org/10.1111/tpj.13212

Utami DW, Barnita K, Yuriah S, Hanarida I (2011) Nucleotide base variation of blast disease resistance gene Pi33 in rice selected broad genetic background. HAYATI J Biosci 18:123-128. https://doi.org/10.4308/hjb.18.3.123

Wang C, Qin TF, Yu HM et al (2014) The broad bacterial blight resistance of rice line CBB23 is triggered by a novel transcription activator-like (TAL) effector of Xanthomonas oryzae pv. oryzae. Mol Plant Pathol 15:333-341. https://doi.org/10.1111/mpp.12092

Wang C, Zhang X, Fan Y et al (2015) XA23 Is an executor r protein and confers broad-spectrum disease resistance in rice. Mol Plant 8:290-302. https:// doi.org/10.1016/j.molp.2014.10.010

Wonni I, Hutin M, Ouédrago L et al (2016) Evaluation of elite rice varieties unmasks new sources of bacterial blight and leaf streak resistance for Africa. Rice Res Open Access 4:1-8. https://doi.org/10.4172/2375-4338. 1000162

Xiang Y, Cao Y, Xu C et al (2006) Xa3, conferring resistance for rice bacterial blight and encoding a receptor kinase-like protein, is the same as Xa26. Theor Appl Genet 113:1347-1355. https://doi.org/10.1007/ s00122-006-0388-X

Yu Y, Streubel J, Balzergue S et al (2011) Colonization of rice leaf blades by an African strain of Xanthomonas oryzae pv. oryzae depends on a new TAL effector that induces the rice nodulin-3 Os11N3 gene. Mol Plant-Microbe Interact 24:1102-1113. https://doi.org/10.1094/MPMI-11-10-0254

Zhang J, Yin Z, White F (2015) TAL effectors and the executor $R$ genes. Front Plant Sci 6:1-9. https://doi.org/10.3389/fpls.2015.00641

Zhang B, Zhang H, Li F, et al (2020) Multiple Alleles Encoding Atypical NLRs with Unique Central Tandem Repeats in Rice Confer Resistance to Xanthomonas oryzae pv. oryzae. Plant Commun 1:100088. https://doi.org/10. 1016/j.xplc.2020.100088

\section{Publisher's Note}

Springer Nature remains neutral with regard to jurisdictional claims in published maps and institutional affiliations. 